AUTHORS:

Dr R. Venketsamy ${ }^{1}$

Dr N. Sing ${ }^{1}$

Ms Lyndsey Smart ${ }^{1}$ iD

AFFILIATION:

${ }^{1}$ University of Pretoria

DOI: http://dx.doi.

org/10.18820/2519593X/pie.v38.

i2.08

e-ISSN 2519-593X

Perspectives in Education

2020 38(2): 118-137

PUBLISHED:

04 December 2020
Published by the UFS

http://journals.ufs.ac.za/index.php/pie

(-) Creative Commons

With Attribution (CC-BY)

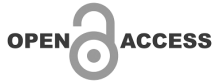

\section{TEACHERS' PERCEPTIONS IN CREATING AN INVITATIONAL LEARNING ENVIRONMENT IN CULTURALLY DIVERSE FOUNDATION PHASE CLASSROOMS}

\section{ABSTRACT}

South Africa is characterised by its vast cultural diversity, and the current classrooms are filled with learners from multicultural and multilingual backgrounds. This cultural diversity has an impact on the classroom climate. The classroom climate is seen as a major determiner of classroom behaviour and learning. Research surrounding classroom practice is changing the way teachers organise their learning spaces as well as their methods of teaching and learning. This paper aimed to gain insight into the teachers' perceptions of the creation of invitational learning environments, using the Invitational Learning Theory as the basis. A qualitative case study involving methods such as focus group interviews with teachers and document analysis containing teachers' notes were examined through the lens of the Invitational Learning Theory of Purkey and Novak. The results indicated that the learning environment plays a significant role in teaching and learning. Teachers noted that when the learning environment was friendly and conducive, learners showed greater enthusiasm to participate in classroom activities. If classrooms were inviting, neatly organised and well-arranged, learners showed a willingness to learn and accepted responsibility for their learning. Teachers noted that learners would go to a specific subject table, for example, mathematics or literacy, and engage in peer learning with the materials.

Keywords: Invitational Learning Theory, invitational environments, diverse culture; five powerful "Ps"

\section{INTRODUCTION}

The changing landscape of South African schools, post1994 has become highly diversified. Glancing across the school environment, it is observable that schools are a platform of learners from multicultural and multilingual backgrounds. Classroom environments are diversified; thus, cultural factors have an impact on the classroom climate. The classroom environment is seen as a key determiner of learner behaviour and learning therefore understanding 
how to establish and maintain a positive classroom climate is seen as a basic requirement to improving schools (Adelman \& Taylor, 2005). Ginsberg (2015) states that when a learning environment acknowledges social behaviour and identifies cultural awareness, learners can become "knowledge builders", instead of "knowledge resisters". Examining reports on academic progress in South African schools raises concerns surrounding the classroom climate and the role of the teacher. This problem seems to perpetuate itself repeatedly. Large classes, poor quality teaching and learning, lack of resources and an uninviting classroom environment have all contributed to the poor performance of learners in national and international assessments (Taylor, 2011). Studies by Steyn (2010) indicated that invitational pratices have a significant impact on the quality of learning and teaching.

The aim of this paper was to gain deeper insight into the teachers' perceptions of the creation of invitational learning environments by using the Invitational Learning Theory framework of Purkey and Novak (1996) in the Foundation Phase. This paper was guided by the primary research question:

How do teachers perceive and create an inviting learning environment in culturally diverse Foundation Phase classrooms?

According to Purkey and Novak (1996, 1988 \& 1984) and Purkey and Schmidt (1990), Invitational Theory tries to find explanations for phenomena and provides a means of intentionally beckoning people to realise their unlimited potentials in areas of worthwhile human endeavour. Its main purpose is to make life a more satisfying and enrichening experience. Purkey (1991) states that the Invitational Learning theory suggests that to facilitate learning, learners should be provided with an environment (five "Ps") that is optimally inviting. These five Ps are represented in Table 1 below.

Table 1: The five Ps identified by Purkey

\begin{tabular}{|c|c|c|c|c|}
\hline People & Places & Policies & Programmes & Process \\
\hline $\begin{array}{l}\text { Teachers and } \\
\text { staff } \\
\text { (both } \\
\text { teaching and } \\
\text { non-teaching). }\end{array}$ & $\begin{array}{l}\text { Physical } \\
\text { attributes of } \\
\text { the classroom } \\
\text { and school. }\end{array}$ & $\begin{array}{l}\text { Written and } \\
\text { unwritten rules } \\
\text { regarding } \\
\text { procedures. } \\
\text { This includes } \\
\text { policies on grading } \\
\text { and discipline. }\end{array}$ & $\begin{array}{l}\text { Curriculum and } \\
\text { content for learners. } \\
\text { This includes } \\
\text { programmes of } \\
\text { wellness and parent } \\
\text { participation. }\end{array}$ & $\begin{array}{l}\text { Examines } \\
\text { how the other } \\
\text { four Ps are } \\
\text { conducted. }\end{array}$ \\
\hline
\end{tabular}

The Invitational Learning Theory outlines five domains that exist in almost every environment that contribute to the success or failure of human endeavour. These domains are referred to as the "five Powerful Ps" and consist of people, places, policies, programmes and processes. The Powerful "Ps" create an ecosystem in which the individual exists (Purkey, 1991). Each of the five Ps identifies elements that teachers are expected to adhere to for successful invitational teaching and learning. A starfish analogy is used to illustrate the five powerful Ps. When these are applied with steady and persistent pressure, it is easier to overcome the biggest challenges in a classroom. Just as a starfish gently and continuously uses each of its arms in turn, to keep steady pressure on the one oyster muscle until it eventually opens, so will teachers in the classroom meet their challenges successfully by paying close attention 
to the five powerful "Ps" (Purkey \& Novak, 2015). Figure 1 below depicts the five "Ps" and their elements.

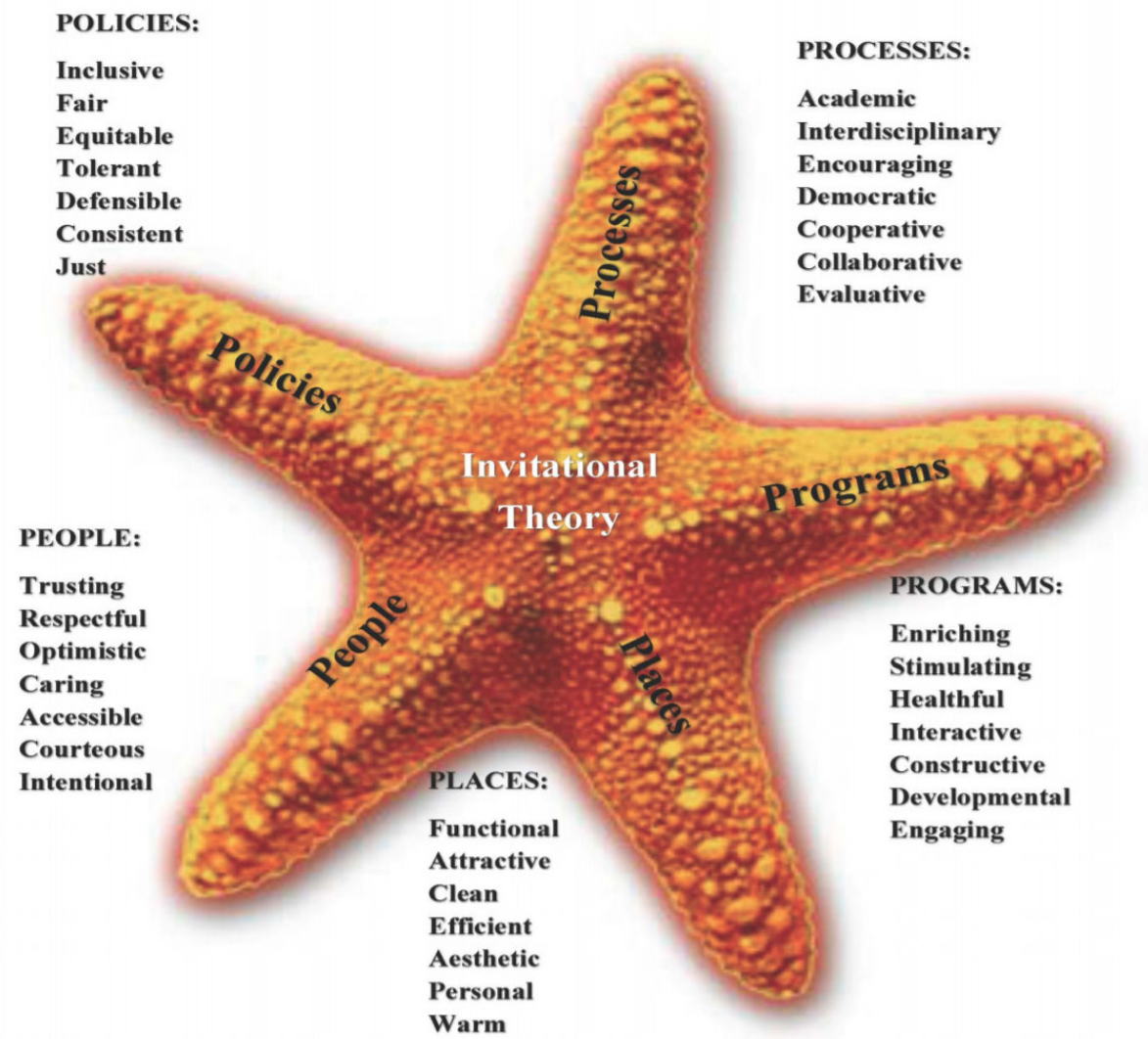

Figure 1: The elements of the 5Ps (from invitationaleducation.org)

\section{LITERATURE REVIEW}

\subsection{Invitational learning environment}

An invitational learning environment, according to Haigh (2011), is an environment created by the teachers and learners to promote quality teaching and learning. He argues that within this environment, learners are positively encouraged or "invited" into the educational experience by the teacher (Haigh, 2011). The invitational pedagogy is constructed on four principles: respect for people, trust, optimism and intentionality and upon five "Ps". Its main contributions address the psycho-geography and the constructive alignment of learning environments and the training of teachers and counsellors.

"Invitational Education (IE) is a theory of practice that aims to create and maintain a human school environment that intentionally and cordially invites individuals to realise their boundless potential in all areas of worthwhile human endeavour" (Friedland, 1999:15; Purkey \& Novak, 2015). IE acquires its foundations from The Democratic Ethos, The Perceptual Tradition and the Self-Concept Theory (Purkey, 1992). The Democratic Ethos is based on the 
belief that all individuals matter and can find growth in self-governance, which is established in IE through deliberate conversation, collaboration and respect (Purkey \& Novak, 2015). Purkey (1991) goes on to explain that invitational teaching and learning is based on five basic assumptions or elements: trust, respect, optimism, intentionality and care. These five assumptions create purpose and directionality in the theory and leads to the creation of an inviting learning environment.

\subsubsection{Trust}

A pivotal aspect of IE understands that human existence is a collaborative activity and all humans are interdependent (Purkey \& Novak, 2015). To create relationships that are inviting, both time and effort are prerequisites to create a trustworthy pattern of interactions between teachers and learners.

\subsubsection{Respect}

"People are able, valuable and responsible and should be treated accordingly" (Purkey, 1991:2). School success is determined by mutual respect from all role-players. Respect should be manifested in all aspects of places, policies, programmes and processes that exist within the school.

\subsubsection{Optimism}

"People possess untapped potential in all areas of human endeavour" (Purkey, 1991:2). The learning environment requires more than just an invitational teacher. It is essential for all roleplayers in the environment, such as the principal, heads of department, teachers, support staff and parents to be optimistic about the process. Human potential has no clear limits and should be considered as boundless. Therefore, in doing so, curricula can be devised, policies can be created, programmes can be supported, processes can be encouraged, physical environments can be established, and relationships maintained (Purkey, 1991).

\subsubsection{Intentionality}

Human potential can be optimally applied by places, policies and programmes that are tailored to address the aspect of invitation as a prerequisite for development. Moreover, it can be used by those who focus on inviting both others and themselves, personally and professionally (Purkey, 1991). Intentionality gives experiences purpose and allows teachers to create environments that have directionality and are purpose driven. Intentionality is essential to consistently invite people to realise their human potential (Purkey, 1991).

\subsubsection{Care}

Caring involves warmth, empathy and positive regard for others; "it provides others with benevolence which filters through in one's personal life as well as the lives of one's fellow humans" (Purkey \& Novak, 2015:2). The element of care is considered as one of the most important elements of IE.

The teacher represents the mechanism of change and together with the learners, they create the tone of the classroom environment. According to Van Deventer and Kruger (2003:3), "teachers play central roles in the development of the tone and ethos that are conducive to teaching and learning and in the process of building a sound culture of learning and teaching in a school". The experiences and opinions of teachers provide a source of knowledge to educational researchers. Teachers hold insightful and real-world experiences of creating an 
environment that nurtures the child socially, physically, emotionally, spiritually and intellectually (Nel, Engelbrecht, Swanepoel \& Hugo, 2013).

\subsection{Levels of intentionality}

The Invitational Learning Theory identifies four levels of invitation for the creation of an inviting learning classroom environment.

\subsubsection{Level one: Intentionally disinviting}

When an environment is intentionally disinviting, it is at the lowest functioning level. On this level, people's actions, places, processes, policies and programmes are drafted to deliberately daunt, demean and demolish (Purkey \& Novak, 2015). Intentionally disinviting functioning might involve a person who is purposely insulting, an intentionally discriminatory policy, a programme that purposely reduces people to functionaries or an environment intentionally left unpleasant and unattractive (Purkey \& Novak, 2015)

\subsubsection{Level two: Unintentionally disinviting}

Teachers who are unintentionally disinviting can be characterised by thoughtless, chauvinistic and condescending behaviour (Purkey \& Novak, 1984). Teaching that can be classified as unintentionally, disinviting is characterised by boredom, busy work and insensitivity (Purkey \& Novak, 1984). Unintentionally disinviting environments often result from a lack of a guiding theory, and although it is not intended, the environment remains disinviting and the damage is still caused (Purkey, 1991).

\subsubsection{Level three: Unintentionally inviting}

Unintentionally inviting environments occur when the teachers are acquainted with the effective strategies, but lack knowledge in their working methods and how to maintain them consistently (Purkey, 1992). Environments that are unintentionally inviting function effectively by chance and teachers are unable to explain why they function so effectively (Purkey \& Novak, 1984). These types of environments lack intentionality; there is no deliberate design to create the environment (Haigh, 2011). Teachers functioning on this level behave in ways that cause students to feel invited, although they are largely unaware of the dynamics involved (Purkey \& Novak, 1984). A lack of intentionality and knowledge in effective inviting strategies poses a problem in creating a consistent, inviting environment.

\subsubsection{Level four: Intentionally inviting}

An invitation is defined as an intentional act designed to offer something of value and benefit for consideration (Purkey 1992). Intentionally inviting allows people to create, maintain and enhance total environments that consistently and dependably invite the realisation of human potential. Teachers that successfully create intentionally inviting learning environments act with sensitivity and consistency (Purkey \& Novak, 1984). Intentionality is a crucial element in creating an inviting learning environment. An intentionally inviting environment can be achieved through purposeful alignment with the five elements of trust, respect, optimism, intentionality and care as well as "the Powerful Ps". 


\section{FACTORS THAT CONTRIBUTE TO THE CREATION OF AN INVITATIONAL LEARNING ENVIRONMENT}

\subsection{Understanding invitational education}

Steyn (2005) states that professional development and teacher education is an essential ingredient for creating effective environments. A case study on the creation of IE at the Christian Alliance College in Hong Kong outlined the need for educators and role-players to understand the concept of IE and the elements that are required to implement the theory. A group of teachers with a deep understanding of IE will be capable of intentionally creating an environment that is inviting (Yin, 2008). By implementing teacher workshops that are hosted and run by the school management, team teachers will be equipped with a deeper understanding of the concept of IE and this will allow invitational environments to form within the classroom.

\subsection{Invitational domains}

Places and physical environments have an impact on the way one feels when in the learning environment. A study by Lipsitz (1984) showed that learners felt ownership and pride when they took part in activities that helped make the environment aesthetically inviting such as cleaning up, decorating areas and building things for the classroom (Purkey \& Stanley, 1991). A similar study by Johnston and Ramos de Perez in 1985 revealed that when the school was well kept and aesthetically pleasing, learners felt cared for (Purkey \& Stanley, 1991). Places should be functional, attractive, clean, efficient, aesthetic, personal and warm in order to invite success (Purkey \& Novak, 2015). An inviting environment is characterised by beautiful and clean school grounds, classrooms, halls, corridors, gardens, offices and teaching-learning equipment (Steyn, 2010). Purkey and Stanley (1991) identified a list of practical indicators for an inviting classroom such as fresh paint; pleasant smell; attractive bulletin boards; lots of books; sanitary environment; flowers on the desk; sunny room; matching colours; positively worded signs; clean windows; living green plants; comfortable temperatures; attractive pictures; conveniently located trash cans; well-arranged furniture; current learner displays; window bird feeders and proper ventilation.

The third "Powerful P" refers to policies. Policies can include those of attendance, academics and discipline. Policies should be easy to understand as well as being developed to maintain the respect of all role-players (Purkey, 1999). Policies should promote equal treatment of all. Policies are aimed to regulate learners as well as the teachers (Purkey \& Stanley, 1991). Rules and procedures regulate human functioning and policies that are inclusive, fair, equitable, tolerant, defensible and consistently invite success (Purkey \& Novak, 2015). Learners respect policies when teachers follow and show respect towards the policies in place (Purkey \& Stanley, 1991). Policies and rules that are written with positive language such as "keep your desk clean" are more effective than rules that are written with negative language such as "do not mess on your desk" (Purkey \& Stanley, 1991). These positive prompts should be considered when designing classroom and school policies.

Purkey and Stanley (1991:69) describe programmes as "curricular and extracurricular activities designed to meet the needs of students". Programmes maintain the needs of people and allow for the successful achievement of goals (Smith \& Hunter, 2007). Programmes that are enriching, stimulating, healthy, interactive, constructive, developmental and engaging invite success (Purkey \& Novak, 2015). All programmes that are introduced into the classroom 
should be evaluated to test whether they are invitational by questioning the programmes' ability to show trust, respect, optimism and intentionality as well as their ability to communicate the learners' ability, value and responsibility. Cooperative learning is a successful method for creating invitational programmes (Haigh, 2011).

Processes regulate the conduct of the other above-mentioned "Ps"; the ways in which the above "Ps" function determine the atmosphere within the environment. Processes that are democratic, collaborative, cooperative and interdisciplinary invite success (Smith \& Hunter, 2007). Purkey (1999) states that processes involve all management and operational processes and that they should create inclusivity, democracy and support that encourage self-development in the learning community. Processes are inseparable from the other four "Powerful Ps". "Process" focuses on the "how" of learning rather than the "what". Teachers can create inviting processes by assigning responsibility, practising democratic activities including cooperative peer teaching and teaching peer counselling (Purkey \& Stanley, 1991).

\subsection{A sense of family}

A "family model" must be developed between staff members, management and learners for learning environments to be fully inviting (Steyn, 2007). The school, especially the classroom, should be viewed as a place of collaboration and cooperation where learners and staff members feel open to express their successes and disappointments. This need for a sense of family is further seen in Yin's 2008 study, where the principal noted that companionship is essential. He described the school as a family rather than a factory and stated that "support and care are needed for staff to become intentionally inviting" (Yin, 2008:11).

\section{THE EFFECTS OF INVITATIONAL LEARNING ENVIRONMENTS ON TEACHING AND LEARNING}

\subsection{Motivation}

Research by Fretz (2015) outlines the relationship between invitational theory and motivation. Invitational learning environments offer a systematic way of communicating positive messages that develop potential and eliminate any threats. Invitational teachers intentionally communicate optimism, respect, trust and care as well as design lessons to ensure that the teaching and the learning environment is inviting (Fretz, 2015). In doing so, learners are provided with a choice that creates responses of interest and commitment to learning, as learners have chosen to engage in learning. Extrinsic motivation often causes learners to lose motivation and interest as their focus becomes orientated around gaining the extrinsic reward offered rather than the value of the learning activity. Promoting the values of the invitational theory encourages learners to identify the value of an education and creates intrinsic motivation.

\subsection{Improved learner outcomes}

Learning environments that are characterised by the elements of IE allow learners to perform better. Where learners feel safe, supported and encouraged, they are more likely to be open to new knowledge and learning; this then enables them to achieve better outcomes. Haigh (2011) states that learning is more effective in environments that is supportive and caring. A case study of Cooper Elementary by Kalec (2004) provides insight into the overall improvement of academic results after the implementation of IE. Involvement and invitational practice in the school made a remarkable difference to the culture and climate of Cooper Elementary that continues to be crucial for learner success (Kalec, 2004). 


\subsection{Embraces cultural inclusion}

The classroom environment is described as comprising four elements: ecology; milieu; social systems and culture (Marais \& Meier, 2012). These four elements of classroom environments find similarities and ties in with Purkey's (1992) "Five Powerful Ps", indicating: people; places; policies; programmes and processes. South African classrooms are culturally diverse, which affects the teaching and learning environment. Respect for other cultures facilitates nuanced meanings. The cultural background sets the foundation for interest and prior knowledge. The invitational learning theory creates learning environments that denote trust, respect and care, allowing for cultural responsiveness and inclusion. Embracing invitational learning in the classroom invites learners to share cultural experiences and backgrounds (Predmore, Kushner \& Anderson, 2017).

Milieu encompasses the interpersonal and social atmosphere of the classroom (Marais \& Meier, 2012). Frisby and Martin (2010) state that interpersonal relationships, based on mutual trust and connection, enhance teacher-learner relationships, aiding in developing positive classroom environments. The first "Powerful P" referring to people, comprises teachers and learners, including their interactions (Marais \& Meier, 2012). Teachers and centre managers play central roles in the development of the tone and ethos that are conducive to teaching and learning and, in the process, a sound culture of learning and teaching in the school (Van Deventer \& Kruger, 2003: 206). In this section of the classroom environment, invitational theory's elements indicating trust, respect, optimism, intentionality and care can be examined (Purkey, 1992).

Ecology encompasses the physical attributes of the classroom (Marais \& Meier, 2012). It also includes classroom composition, class size and classroom management (Miller \& Cunningham, 2011). Studies on class size indicate that the learner-teacher ratio influences the interaction time with each learner, discipline and instruction time. Smaller classes were characterised by low stress and frequent "on-task" behaviour, with fewer discipline challenges (Miller \& Cunningham, 2011). Classroom management strategies such as grouping learners in cooperative settings, leaving learners with a positive perception of grading and learning, class cohesion and a sense of social support (Miller \& Cunningham, 2011). Woolfolk (1995) agrees that the classroom environment should be inviting; learners should feel accepted and encouraged through the classroom display. Purkey's (1992) second "Powerful P" of places examines the physical environment of the classroom (Marais \& Meier, 2012).

Social interactions encompass the formal and informal rules regarding interpersonal relationships in the classroom (Marais \& Meier, 2012). These interactions include aspects of classroom management such as set rules, incorporating Purkey's elements, indicating treating one another with care, respect, trust, optimism and intentionality (Purkey, 1992). When teachers develop positive instructor-student relationships whilst focusing on student needs and projecting care, students improve academically (Barr, 2016). Teaching and learning do not occur only between the instructor and students, but also among students themselves (Hirschy \& Wilson, 2002). A classroom environment with inviting interaction is characterised as compassionate, displaying student-to-student support (Barr, 2016). Purkey's (1992) first, third and fifth "Powerful Ps", of "people" "policies" and "processes" can be used to guide interpersonal interaction between teachers and learners. Democracy, fairness, inclusion, tolerance and consistency should govern all interpersonal interactions (Purkey, 1992). 
Culture refers to the values, belief systems and norms in the classroom (Marais \& Meier, 2012). It also refers to the values and beliefs brought by each unique learner. These include the values and beliefs projected by the teacher. Immense importance is placed on the teacher to model and shape the culture towards a positive and inclusive environment (Bates, 2016). Purkey's first "Powerful P", signifying "people", integrates with culture, as learners and teachers are expected to interact with care, trust, respect, optimism and the intention to create an environment inviting to all people, regardless of their beliefs and value systems (Purkey, 1992). It is important to consider that all programmes project respect for people's various cultures. As Schmidt (2004: 31) states:

[p]rogrammes that neglect or ignore cultural or individual differences or processes adopted for the convenience of an elite few, may disinvite people who feel slighted or set apart from the rest of the population.

\section{THEORETICAL FRAMEWORK}

Invitational learning is based on the Invitational Learning Theory (Purkey 1984), contending that learning is enhanced when learners are invited into the learning environment using improved approaches (Haigh, 2011). According to Haigh (2011), IE was founded by Purkey to persuade learners into meaningful knowledge construction by removing barriers and obstacles to learning, causing learners to be disengaged and unreceptive. The Invitational Learning Theory defines five domains according to Purkey and Novak (1996, 1988 \& 1984). These domains include people, places, policies, programmes and processes. These authors agree that the five basic assumptions are essential in understanding invitational theory. These assumptions, according to Purkey and Novak (1996, 1988 \& 1984) and Purkey and Schmidt (1990). are that:

- people are able, valuable and responsible and should be treated accordingly;

- educating should be a collaborative, cooperative activity between the relevant stakeholders;

- the process is the product in the making;

- people possess untapped potential in all areas of worthwhile human endeavour; and

- this potential can be realised by places, policies, programmes and processes specifically designed to invite development and by people who are intentionally inviting themselves and others, personally and professionally.

Figure 2 below illustrates the sections of Invitational Theory. 


\section{Invitational Theory}

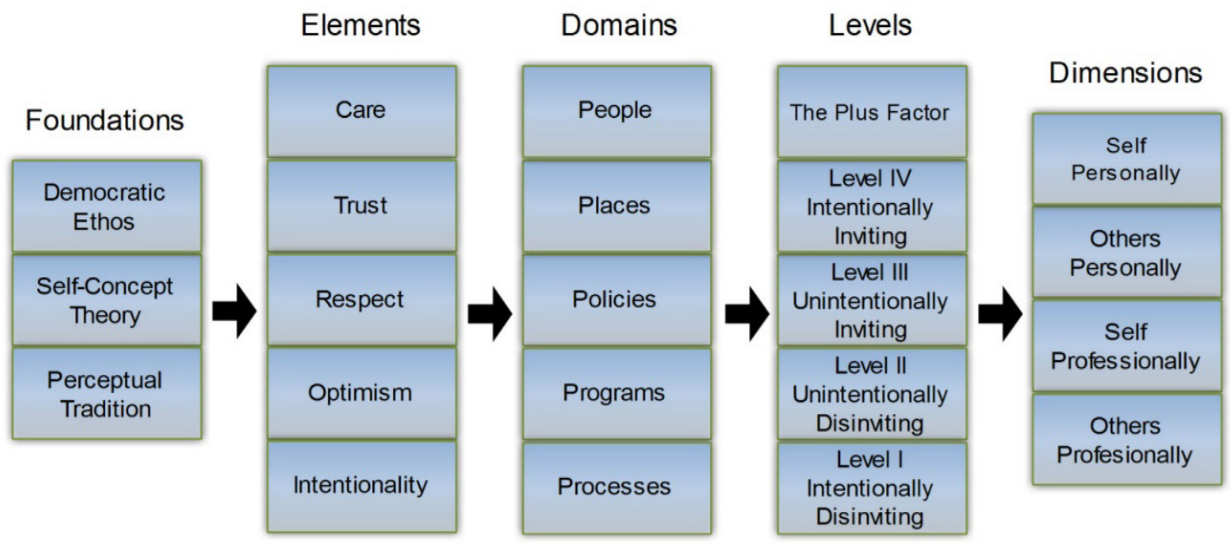

Figure 2: Invitational Theory (Purkey \& Novak, 2015)

Invitational learning aims to make these domains intentionally inviting by cordially encouraging each learner to develop physically, intellectually and emotionally. An invitation is measured through four possible levels: intentionally disinviting, unintentionally disinviting, unintentionally inviting and intentionally inviting.

This research will use Purkey's (1999) four invitational levels to measure the extent of the invitation as perceived by the teacher. In addition, Purkey (1991) identifies four principles of the invitational theory that will be considered, namely respect for people and their difference, trust expressed through cooperation and sense of community as well as optimism regarding the learner's untapped potential and intentionality (Haigh, 2011).

\section{RESEARCH METHODOLOGY}

\subsection{Research design and methods}

It was considered that a qualitative study would be best to provide an in-depth understanding of the phenomenon using an interpretivist research paradigm. An interpretivist research paradigm allows a quest for answers and insight by studying social settings and individuals (Nieuwenhuis, 2016). Qualitative research is characterised as linguistic, meaning-based, naturalistic, exploratory and seeking in its understanding of phenomena (Creswell, 2014; Yanow \& Schwartz-Shea, 2015). This allowed a conversation to take place during interviews that assisted in the gathering of a more well-rounded understanding of the teachers' experiences and interactions with the learning environment.

A case study approach was used as "an intensive study about a person, a group of people or a unit, aimed to generalise over several units" (Gustafsson, 2017:2). A sample of seven Foundation Phase educators was selected. It was envisaged that they would be able to contribute to the answering of research questions with rich information on their perceptions of creating an inviting classroom environment (Nieuwenhuis, 2016). The sample consisted of teachers from Grades 1, 2 and 3 from two schools in the Tshwane District of the Gauteng Province in South Africa. A specific criterion was stipulated in the selection of the participants and the schools. The school and teachers had to be actively involved in attempting to create 
an environment that is inviting and conducive to teaching and learning. All participants in this study were selected using purposive sampling; this study required participants that would accurately represent the population in question (Battaglia, 2011).

Data were collected from semi-structured interviews and classroom observation. The data were transcribed and analysed by organising and sectioning responses into units, synthesising them, identifying patterns as well as ascertaining which data was of importance and needed to be shared.

Permission for the study was granted by the Gauteng Department of Education (GDoE) and all participants gave written and informed consent. They were also made aware that participation was voluntary and that they were able to pull out of the study at any time. Codes were used to ensure anonymity.

\section{RESULTS: DISCUSSIONS AND FINDINGS}

\subsection{Teachers' perceptions of the creation of an invitational learning environment}

Invitational theory focuses on five domains that exist in practically every environment. Purkey and Novak (1984) state that the classroom is an ideal environment in which the five powerful "Ps" can be implemented. The research findings and discussion focused on people, places, policies, programme and processes. The discussion and findings are supported by the theoretical framework, relevant literature and verbatim quotes.

\subsubsection{People}

Teachers perceived the need for an invitational learning environment as a high priority for successful teaching and learning. An invitational learning environment was not only identified as important for learner success but was equally valuable for the teachers' morale, functionality and effectiveness. Haigh (2011) emphasises that invitational theory constructs itself on four principles: respect for people and their differences, trust expressed through cooperation and a sense of community, optimism about the untapped potential contained within each learner and intentionality, which means taking those steps needed to create each learning invitation and addressing it to each learner (Purkey \& Novak, 2008). To this PT 1 stated:

\section{As Foundation Phase teachers, we must make sure that our classrooms look welcoming to our learners. Our children must love to come into the classroom. It is a place of learning and safety for them. Some of our children come from very broken homes, and therefore it is my job to make sure they are safe in this environment. They must come to a place where they feel loved and appreciated. (PT 1)}

PT 3 added: "Our classrooms are so diversified, as teachers we must show love, trust, respect and affection to our learners. They must know that we care for them just like their parents."

Purkey and Novak (1996) expressed that people are able, valuable and responsible and should be treated as such. To ensure that their young learners felt trusted and cared for, teachers modelled caring and loving behaviours in their classrooms such as praising their learners for good work, hugging them when the learners needed a hug, and appreciating their learners' efforts in their schoolwork without making children feel unappreciated or unloved. 
PT 4 explained: "The teachers must allow full attention towards them and even give hugs and individual attention when needed."

PT 2 indicated that as teachers,

We must take the time to listen to learners, having one-on-one conversations and taking an interest in their personal lives. Our children come from different backgrounds, and they have their own stories to tell. My job is to listen and appreciate their individual stories and experiences.

Within their Powerful five Ps, Purkey and Novak (2015) state that teachers must be "professionally inviting with others", that is treating their young learners as valuable individuals, acting carefully, ethically and respectfully. It was noted that children began to understand and appreciate cultural differences in their classes. Establishment of healthy relationships and positive social interactions in the classroom can be the main prerequisites to start forging an inviting atmosphere (Haidari \& Karakus, 2019).

Most teachers indicated that they always made themselves approachable to learners. They made a point of encouraging learners through positive reinforcement and rewards such as stickers and behaviour certificates. Teachers used positive and inviting communication when addressing learners, helping learners to focus on what they were able to do and how they were able to improve, rather than focus on what they were not able to achieve.

\subsubsection{Place}

Nurturing a sense of emotional and psychological safety is essential in every learning environment to facilitate effective teaching and learning opportunities (Holley \& Steiner, 2005). A safe and desirable learning environment requires creating participative and rich learning opportunities for the learners so that they feel connected to their teacher and classmates (Frisby, Berger, Burchett, Herovic \& Strawser, 2014).

The classroom environment is an important space for learners in the school. This is an environment where they are safe and secure to venture and learn. According to Haidari and Karakus (2019), young learners are sensitive to negative and extreme behaviours, which can easily result in distraction, a sense of fear and unlearning.

Teachers identified the "place" domain of an invitational environment as very important; the teachers felt the physical environment such as the decorations, posters, lighting, ventilation and learning resources were vital when creating an invitational learning environment.

In the interview, PT 5 mentioned, "In my class the children get involved in organising the classroom furniture, learning corners for example the library corner, maths corner and lifeskills corner".

PT 4 said, "I allow my children to make charts for me. They feel very proud to pin up the charts on the walls. You must see the care they take for their charts. I have noticed that they take their friends along and read the information off the charts". To this PT 7 added, "Most of my learners are eager to pin up their artwork on a Friday. Each week, I try to allow a different group of learner[s] to post up their artwork; it's difficult to have 45 learners artwork up on the walls in the class. These corners are set according to the learners' needs." Purkey and Novak (2015) state that learning spaces should be functional, attractive, clean, personal, aesthetic and warm. 
The teachers indicated that they have created personal spaces for each learner using nametags and spaces for the storage of their items; these ensured learners felt a sense of belonging in the environment.

Three teachers (PT 3; PT 5 and PT 7) expressed an understanding of an invitational learning environment as follows: "An invitational environment is neat, tidy and decorated. It must look inviting in that it must be pleasant to be there". The teachers highlighted the importance of the learning environment being safe and comfortable as well as aesthetically appealing to children. The teachers included the following strategies to ensure their classrooms were inviting and conducive for learning; brightly coloured walls and charts, clean and neat functional bookshelves as well as reading corners. It should have appropriately marked up areas with clearly visible signs and instructions for all learners. All teachers agreed that an invitational learning environment would result in educators and learners taking pride in their schools and striving for greater academic success. The teachers encouraged learners to respect each other's space and learning areas. The teachers helped promote these values by sharing the responsibilities of classroom jobs and allowing learners equal opportunities. An invitational learning environment must be ready to ease classroom pressure and allow learners to become educated as worthy members of society (Haidari \& Karakus, 2019). All teachers agreed that creating a safe space in the classroom where learners' identity and individuality are valued and nourished, is essential in enforcing learners' connectedness to the learning environment.

\subsubsection{Policies}

A controlled classroom environment is essential for effective learning, good teacher relationships and peer collaboration. Many teachers commonly find that approximately onehalf of all classroom time can be taken up with activities other than instruction (Walter \& Frei, 2007). To facilitate learning, there needs to be order in the classroom. Order in a classroom simply means that within acceptable limits, the students are following the programme of action necessary for a particular classroom event to be realised in the situation. Purkey and Novak (2015: 4) clearly articulate that when policies are drawn up in classes to promote invitational teaching and learning, these polices should be "inclusive, fair, equitable, tolerant, defensible, consistent and just".

In response to classroom management and discipline, PT 7 stated,

"In the beginning of the year, together with my learners we decided on basic ground rules which we should obey in our class. Each learner was given an opportunity to write down two basic ground rules which they thought were important to respect. We decided on basic six rules for our grade 2 class. I felt that six was enough for them to remember for the first term.

Other teachers also indicated that they involved their learners in deciding on classroom rules.

According to Chandra (2015), classroom management aims at establishing learner selfcontrol through a process of promoting learner behaviour and achievement. According to Evertson and Weinstein (2006), classroom management seeks to establish and sustain an orderly environment so that learners can engage in meaningful academic learning and to enhance social and moral growth. 
One teacher said: "I have a cleaning roster in my class. Learners know which week they are responsible to clean the classroom. Everyone has a turn to keep the classroom clean. It is not pleasant to be in a dirty class." In the same way, teachers addressed the aspects of consistency and equality; teachers strove to include all learners equally and use this same consistency when applying rules. The teachers treated each learner with dignity regardless of their behaviour. The teachers created discipline strategies that were invitational by using positive reinforcement, time-out and motivational reward charts. A participating teacher supported and posited:

Stickers for good behaviour are a method for creating care. Following a learner's individual progress and taking an interest in it makes the learners feel like they are not "lost in a crowd". I make individual name cards for each child to put on their desk, so they know I recognise each of them. I also put in an effort to learn their names (PT 6).

All teachers agreed that through democratic participation in the classroom, teachers could manage classroom discipline and behaviour. The teachers and learners must be committed to teaching and learning to overcome classroom management. Learners and teachers should be punctual, feel and believe that the classroom policies and rules are for the benefit of all who enter the learning environment. The teacher and learners must be willing to accept responsibility for classroom management and behaviour.

\subsubsection{Programmes}

Purkey and Novak (2015) describe invitational programmes as enriching, stimulating, engaging, developmental, interactive and constructive. Participants had their opinions on the content they taught as well as described the steps they took to ensure their programmes are engaging and constructive. Participants provided insight into how programmes could be more enriching. All the participants agreed that when creating programmes that were engaging and constructive, teachers should incorporate the use of teaching resources and multi-media to make the lessons child-centred and relevant. They stated that the use of concert objects and exciting resources kept learners engaged and focused on the activity for longer. PT 5 indicated that,

In my school we design lessons to be interactive with both peers and objects, helping learners to strengthen knowledge through conversation and practical tasks. We try to make the content relevant to the learner's life-wor[l]d and this helped our learners to feel as if what they were learning was valuable to their lives.

Briggs (2014) stated that learners need a personal connection to the learning material, whether that is through engaging them emotionally or connecting the new information with previously acquired knowledge.

PT 4 shared her view about the learning programmes in her class:

Although CAPS is very prescriptive in what we must teach, my principal has allowed us to adapt the lessons to the learners' situational context. Most of our learners come from the townships. Instead of teaching them about mining, I teach them about farming. My learners are encouraged to go and start their own food gardens at home in small spaces or containers.

Purkey and Novak (2015) and Briggs (2014) agree that relevance is a key factor in intrinsically motivating learners to implement their learning. By establishing the personal and 
real-world relevance, learners are provided with opportunities to relate their subject matter to the world around them.

PT 5 explained that she adapted some of the topic and made them relevant to learners and tried to make the lesson about the learners, for example "I have taken my Star Story Readers and included the learners' names in the story. Instead of Kathy, I name the little girl Refilwe. I noticed that my learners enjoyed reading books with their names in it". During the observation lesson, it was noted that the teacher related content and examples to learners on a personal level. When she taught word problems, she used the names of the learners. As an observer, I noticed how excited these learners became and how quickly they tried to solve the word problems. The learning atmosphere became more inviting, friendly and conducive to teaching and learning. Haigh (2011) advocates cooperative teaching and learning as a successful method for creating programmes that are inviting.

Concern raised by teachers regarding the implementation of successful programmes is the class-size. Most teachers felt that their classes were too large to teach successfully in small groups and individually. However, PT 1 indicated, "I plan in advance and make use of a wide variety of media and posters. Although my class is not ideal for small group teaching, I use group leaders and reading mums to help out with small group teaching". Purkey and Novak (2015: 1) state that "people possess untapped potential in all areas of worthwhile human endeavour". PT 1 stated as a teacher, "I have seen the importance of parental involvement with schools. They can make a big difference in supporting us in the classroom". According to Waterford.org (2018), when parents and teachers work together to establish a thriving classroom, the effect on their school is profound.

PT 4 and PT 3 felt that their lessons would be more enriching if they had more time and less work from the Annual Teaching Plan (ATP), less administration and fewer learners in the class. PT 5 stated more individualised learning as well as more free play would create more enriching and constructive lessons. PT 1 and PT 2 both felt access and use of technology would assist them in providing lessons that are more enriching and stimulating. PT 1 said:

We have white/smart boards in the classroom. Having internet to show the learners videos would actually really help. More technology causes us to use our own equipment. It is sometimes hard for all 40 learners to see the small screen.

All teachers agreed, saying that lessons and programmes would be more enriching if a teacher had fewer learners per classroom. Internet, data projectors and laptops can also make a difference.

Most teachers agreed that collaboration and cooperation were incorporated into all lessons using group work, work that was done on the carpet, in pairs or tasks that were done in class. Purkey and Stanley (1991) state that cooperative learning creates opportunities for group and individual accountability. The teachers created the opportunity to teach skills such as conflict resolution to a group and working as a team despite their differences. An opportunity to show the value of working collaboratively in a team was presented. The teachers extended this into the classroom by sharing the responsibilities of classroom jobs so learners collaborated to achieve a common goal.

Democracy was established by treating all learners the same and involving learners in decision-making. The teachers did not shy away from celebrating learner differences and making curriculum differentiation a norm in their classrooms. The children understood that 
they were unique and did not find it strange that they needed different approaches to be able to learn. A teacher involved in the study said, "My children are used to curriculum differentiation, as they do not tease each other, and they understand that different children learn differently". The learners were involved in decision-making, such as creating classroom rules. This shows that their thoughts were valued by their teacher and their class.

\subsubsection{Processes}

All teachers agreed with Purkey and Novak (2015) that for the creation of an invitational learning environment, democratic principles should be applied; there should be collaborative teaching and learning, the learning environment must be encouraging and cooperative. Academic success should be encouraged and learners who do not succeed academically should be motivated to succeed. Purkey and Stanley (1991) suggest holding mock elections, trials and debates to encourage and practise the use of democratic values in the learning environment. PT 4 and PT 5 agreed with PT 1, who stated, "Treat all learners the same, always consitently. All learners are treated the same and I always try and be consistent. We are all the same and should be treated equally". PM7 agreed that, "All children must be equal stakeholders in the classroom. A democratic ethos can be achieved by allowing everyone in class to have a chance to participate and chores must be divided equally". To this PT 6 opined,

We can achieve democracy by encouraging diversity and curriculum differentiation. We are all different in life and it's important to view our differences as something that makes us unique rather than something that sets us apart in a negative manner. We must be like beautiful unicorns.

Purkey and Stanley (1991) identify an effective invitational teacher as one who can attend to the "social side of learning", meaning the process of working collaboratively to achieve a common set goal. A sense of encouragement is an important ingredient in an invitational learning environment for all involved to realise their goals and reach their full potential. PT 2 said "Positive reinforcement and praising excellent efforts work well. Positive feedback for good behaviour helped much. Invitational communication must be used as a encouraging tool. Praise them good or bad".

During the classroom observation, I noticed that teachers walked around the classroom monitoring the progress of learners and providing encouragement. PT 2, PT 3 and PT 4 used a coupon system to keep learners encouraged. They used stars or stickers as tokens of appreciation.

Yin (2008:16) asserts that educational change and effectiveness depend on people who work collaboratively. Collaboration and cooperation are interdependent with invitational education. Collaboration is required on all levels of the school system. For the environment to be invitational, each individual impacts the environment (Steyn, 2005). Teachers described several techniques to promote collaboration amongst learners. PT 1 used group work as well as encouraged learners to support and encourage each other. PT 4 similarly used group work, as she stated, "Learners do lots of group work, and that helps them to read together, build together and tolerate each other even if we are not always fond of each other". PT 3 indicated, "It is not only about what they do in a group, but it is about learning the skills needed to work in a group. In life, you are not going to like everyone, but you are going to have to work with them". 


\section{RECOMMENDATIONS}

The aim of this paper was to gain insight into the teachers' perceptions of the creation of invitational learning environments. The findings of this research bring to light the following recommendations:

A people-centric environment focuses on people and making them the number one priority. Purkey and Novak (2015) articulate throughout their theory that people are able, valuable and responsible. They should be treated with respect, care and love. In the classroom environment, it is recommended that teachers create an environment whereby learners show respect, tolerance and care for each other. This can be done through the topic "personal and social well-being" in the Life Skills CAPS. The teachers and learners can incorporate an inviting attitude in their professional demeanour - treating people as valuable individuals, acting carefully, ethically and respectfully with regard to all five "Ps", but also strongly promoting the same attitudes among others, cooperating with others professionally, remaining optimistic and behaving ethically.

Blackburn (2018) states that the first step in creating an inviting environment is to build a relationship with your learners. This relationship should be based on mutual trust, knowledge and authority. This relationship will invite learners to explore and venture in a well-organised, appropriately labelled classroom. The school environment (place) should be a safe haven for learners where they are free to venture, explore their interpersonal and intrapersonal relationship and learn without fear or anxiety. Purkey and Novak (1984) recommend that teachers should give learners an opportunity of clearly organising and planning their classroom settings. It is recommended that teachers, together with their learners, develop a code of conduct for their classroom (classroom rules), develop guidelines for positive behaviour and the reinforcement of such behaviours. It is recommended that every learner should have their own personal space in the classroom for which they become accountable. These personal spaces should be labelled appropriately, brightly coloured and visible. Learners can also become involved in cleaning their classrooms and learning space, making it inviting for teaching and learning. It is recommended that classrooms should be organised neatly and methodically to control confusion and stress. The teachers and learners always need to know where to find their books and learning materials.

Purkey and Novak (2015) state that educating should be a collaborative, cooperative activity. It is recommended that classroom policies and processes should be clearly outlined and articulated from the time the young learner enters the classroom. Policies should be drawn up democratically, allowing every learner to participate in the consultation and advocacy of the policy. In the classroom, policies such as discipline, code of conduct, work ethics, homework guidelines and bullying should be developed age-appropriately. It is also recommended that within these policies, certain processes should be included if transgressions occur. The policies and processes for each classroom must be transparent and acceptable (inviting) to all learners. These policies and processes should not deter learners' learning (disinviting) or be restrictive from being themselves.

In the book Inviting Classroom Success, Purkey and Novak (1984) articulate that to create an invitational learning environment free from stress and confusion, teachers need to plan lessons thoroughly. It is recommended that lesson plans should allow learners to participate in the learning process actively. In planning their programmes, teachers should teach young 
learners to set measurable academic and behaviour goals. Young children are readily invited to routines. It is recommended that teachers set clear routine activities that learners can follow.

To further create an invitational learning environment, it is recommended that teachers should search for learners' strengths and build on them. Include activities in the lessons that allow every learner to feel a measure of success.

To create a positive classroom discipline system, teachers should uphold the classroom rules developed together with learners and give them ownership in the discipline process. Teachers should be careful from straying away from these rules. They need to keep to the rules and fairly and consistently execute the consequences. It is recommended that teachers use negative consequences infrequently by reinforcing positive behaviours with a reward system. Learners should be disciplined in private. This demonstrates respect and protects the learner from public humiliation.

\section{CONCLUSION}

Most significantly, the study found that educators offered valuable information regarding successful strategies in creating and maintaining an invitational learning environment. While strategies varied slightly from teacher to teacher, a core atmosphere of care, love and individual focus dominated most techniques. Human existence, according to Purkey and Novak (2015), is a cooperative activity where the process is as important as the product. To develop and sustain inviting relationships requires the time and effort to establish trustworthy patterns of interaction. Caring is at the core of the inviting stance. Finally, human potential can best be realised by places, policies, process and programmes specifically designed to invite development and by people who are personally and professionally inviting with themselves and others. Similar to the starfish analogy, teachers can continuously persevere to create an invitational learning environment by continuously applying the five powerful "Ps". This study provided valuable insights into the perception of teachers in creating an invitational learning environment.

\section{REFERENCES}

Adelman, H. \& Taylor, L. 2005. Classroom climate. Encyclopaedia of School Psychology, 1(43): 89-421. https://doi.org/10.4135/9781412952491.n43.

Bates, T. 2016. Building an effective learning environment. Available at https://www.tonybates. ca/2016/02/22/building-an-effective-learning-environment/

Battaglia, M. 2011. Purposive sample. In Encyclopedia of survey research method, (pp. 645647). Thousand Oakes, CA: Sage.

Briggs, S. 2014. How to make learning relevant to your students (and why it's crucial to their success.). Available at: https://www.opencolleges.edu.au/informed/features/ how-to-make-learning-relevant/

Chandra, R. 2015. Classroom management for effective teaching. International Journal of Education and Psychological Research, 4(4): 13-15.

Creswell, J.W. 2014. Research design: Qualitative, quantitative, and mixed methods approaches, 4th ed. Thousand Oaks, CA: Sage. 
Evertson, C.M. \& Weinstein, C.S. 2006. Classroom management as a field of inquiry. In C.M. Evertson \& C.S. Weinstein (Eds.). Handbook of classroom management: Research, practice, and contemporary issues (pp. 3-16). Mahwah, NJ: Lawrence Erlbaum Associates.

Frisby, B.N., Berger, E., Burchett, M., Herovic, E. \& Strawser, M.G. 2014. Participation Apprehensive Students: The influence of face support and instructor-student rapport on classroom participation. Communication Education, 63: 105-123. doi:10.1080/036 34523.2014.881516. https://doi.org/10.1080/03634523.2014.881516.

Fretz, J. 2015. Creating optimal learning environments through invitational education: An alternative to control-oriented school reform. Journal of Invitational Theory and Practice, 21: 23-30.

Friedland, S. 1999. Violence reduction? Start with school culture. School Administration, 56(6): 14-15.

Ginsberg, M.B. 2015. Making diverse classrooms safer for learning. Culturally Diverse Classrooms, 72(6): 25-28.

Gustafsson, J. 2017. Single case studies vs. multiple case studies. London: Halmstad.

Haidari, S.M. \& Karakus, F. 2019. safe learning environment perception scale (SLEPS): A validity and reliability study. International Journal of Assessment Tools in Education, 6(3): 444-460. https://doi.org/10.21449/ijate.550393.

Holley, L.C. \& Steiner, S. 2005. Safe space: Student perspectives on classroom environment. Journal of Social Work Education, 41(1): 49-64. https://doi.org/10.5175/ JSWE.2005.200300343.

Haigh, M. 2011. Invitational education: Theory, research and practice. Journal of Geography in Higher Education, 35(2): 299-309. https://doi.org/10.1080/03098265.2011.554115.

Kalec, A. 2004. Invitational education at Cooper elementary. Journal of Invitational Theory and Practice, 10: 73-81.

Lipsitz, J. 1984. Successful schools for young adolescents. New Brunswick. NJ. Transaction Books.

Marais, P. \& Meier, C. 2012. Education management in early childhood development. Pretoria: Van Schaik.

McNamara, C. 2006. Authenticity consulting, LLC. Available at https://authenticityconsulting. com/pubs/CN-gdes/CN-FP.htm

Miller, A \& Cunningham, K. 2011. Classroom environment. Farmington Hills, MI: Gale Group.

Moswela, B. 2006. Teacher professional development for the new school improvement. International Journal of Lifelong Education, 25(6): 625-632. https://doi. org/10.1080/02601370600989350.

Nel, M., Engelbrecht, A., Swanepoel, H. \& Hugo, A. 2013. Embracing diversity through multilevel teaching. Cape Town: Juta.

Nieuwenhuis, J. 2016. Introducing qualitative research. In K. Maree (Ed.). First steps in research, 2nd ed. Pretoria: Van Schaik.

Predmore, C., Kushner, R. \& Anderson, C. 2017. So, that is what you said? Journal of Invitational Theory and Practice, 23: 91-96.

Purkey, W.W. 1991. What is invitational education and how does it work? London: Oxford University Press. 
Purkey, W.W. 1992. An introduction to invitational theory. Journal of Invitation Theory and Practice, 1(1): 5-14.

Purkey, W.W. \& Novak, J.M. 1984. Inviting school success. Belmont, CA: Wadsworth, Inc.

Purkey W.W \& Novak J.M. 2015. An introduction to invitational theory. Available at https://www. invitationaleducation.org/wp-content/uploads/2019/04/art_intro_to_invitational_theory-1.pdf

Purkey, W.W. \& Novak, J.M. 1988. Education: By invitation only. Bloomington: Publications, PDK.

Purkey, W.W. \& Novak, J.M. 1996. Inviting school success: A self-concept approach to teaching, learning, and democratic practice, 3rd ed. Belmont, CA: Wadsworth Publishing.

Purkey W.W \& Novak J.M. 2015. An Introduction to invitational theory .Journal of Invitational Theory and Practice, 1(1): 5-15.

Purkey, W.W. \& Schmidt, J. 1990. Invitational learning for counseling and development. Ann Arbor, MI: Eric/Caps Clearinghouse.

Purkey, W.W \& Stanley, P. 1991. Invitational teaching, learning, and living. Washington DC: National Education Association.

Shaw, D., Siegel, B. \& Schoenlein, A. 2013. Tenets of invitational theory and practice: An invitational glossary. Journal of Invitational Theory and Practice, 37: 30-37.

Smith, K. \& Hunter, M. 2007. Inviting school success: Invitational education and the art class. Journal of Invitational Theory and Practice, 13: 8-15.

Steyn, G. 2005. Implementing professional development in invitational education. African Education Review, 2(2): 258-278. https://doi.org/10.1080/18146620508566304.

Steyn, G. 2010. Creating intentionally inviting schools through professional development: An appreciative inquiry. Koers, 75(4): 873-897. https://doi.org/10.4102/koers.v75i4.111.

Steyn, T. 2007. Adhering to the assumptions of invitational education: A case

study. South African Journal of Education, 27(2): 265-281.

Taylor, N. 2011. The national school effectiveness study (NSES). Summary for synthesis report. Cape Town: Jet Education Services.

Van Deventer, I. \& Kruger, A. 2003. An educator's guide to school management skills. Pretoria: Van Schaik.

Wallace, S., Acker-Hocevar, M. \& Sweatt, O. 2001. Developing an open systems view for assessing education leadership. Journal of School Leadership, 11: 241-256. https://doi. org/10.1177/105268460101100306.

Waterford.org. 2018. How parent involvement leads to students success. Available at https:// www.waterford.org/education/how-parent-involvment-leads-to-student-success/

Woolfolk, A. 1995. Creating learning environments. Education Psychology, 443-477.

Yanow, D. \& Schwartz-Shea, P. 2015. Interpretation and method: Empirical research methods and the interpretive turn, 2nd ed. New York: Taylor \& Francis. https://doi. org/10.4324/9781315703275.

Yin, L. 2008. Creating an inviting school: A case study on introducing invitational education (IE) in a secondary school in Tuen Mun. Available at http://www.cactm.edu.hk/ IE/document/ ie2008.pdf 